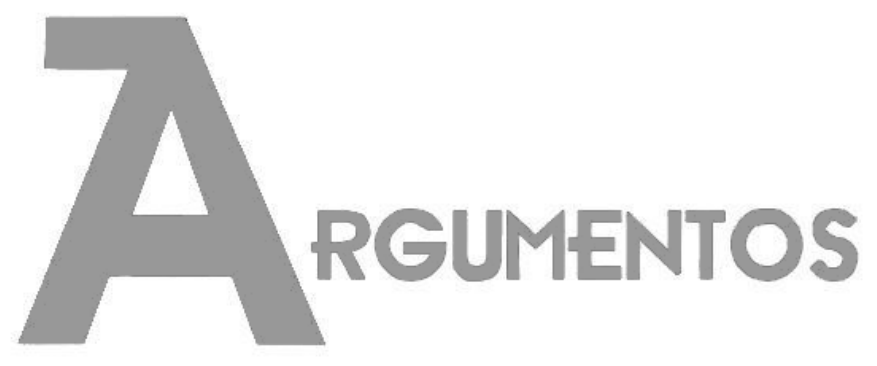

Vol. 16, n. 2, jul./dez. 2019 ISSN: 2527-2551 (online)

http://www.periodicos.unimontes.br/argumentos

\title{
Apresentação do dossiê \\ Pensamento social e político brasileiro: buscar no passado as explicações para o presente político e social brasileiro
}

\author{
José Henrique Artigas de Godoy ${ }^{1}$ \\ Moacir de Freitas Junior ${ }^{2}$
}

\begin{abstract}
Resumo: Os estudos do campo do Pensamento Social e Político Brasileiro refletem sobre o que somos e, ainda mais, sobre o que queremos e podemos ser. São indagações que, de tempos em tempos, voltam à tona como desafios presentes em meio a crises pronunciadas. Nestas circunstâncias, é aconselhável voltar aos clássicos para que não nos esqueçamos que o presente é, antes de tudo, resultado do passado, e de um passado que primou por manter elos com a tradição, com os costumes, com as formas de dominação, de hierarquia social, de organização política. Estas características históricas únicas nos conduzem a uma insistente volta ao passado para encontrar os marcos das crises presentes e para prospectar as alternativas futuras. Por isso a importância reiterada de retorno aos clássicos no esforço de refazer os caminhos dos que vieram antes de nós, para nos compreendermos melhor. Seguindo esta tradição, o dossiê apresenta estudos sobre grandes intérpretes deste campo de pesquisa, como Florestan Fernandes, Octávio Brandão, José Guilherme Melquior, José de Alencar e Leandro Tocantins, cada um com sua especificidade e ideias próprias sobre o Brasil, nosso povo, identidade, integração e outros temas de igual relevância, análises cujo momento de crise política e social torna ainda mais relevante.
\end{abstract}

Palavras-chave: Brasil. Interpretações. Ideias.

\section{Presentación del dossier}

Pensamiento social y político brasileño: búsqueda de las explicaciones pasadas para la actualidad política y social brasileña

Resumen: Los estudios en el campo del pensamiento social y político brasileño reflexionan sobre lo que somos y, aún más, sobre lo que queremos y podemos ser. Estas son preguntas que, de

\footnotetext{
${ }^{1}$ Doutor em Ciência Política pela Universidade de São Paulo, Brasil, é professor associado do Departamento de Ciências Sociais (DCS) e do Programa de Pós-Graduação em Ciência Política e Relações internacionais (PPGCPRI) do Centro de Ciências Humanas Letras e Artes da Universidade Federal da Paraíba (CCHLA-UFPB), Brasil. E-mail: jhartigasgodoy@gmail.com. ORCID: https://orcid.org/0000-00029580-1841

${ }^{2}$ Doutor em Ciências Sociais pela Unesp de Araraquara, Brasil, é professor adjunto do Instituto de Ciências Sociais - INCIS e do Programa de Pós-Graduação em Ciências Sociais do INCIS, da Universidade Federal de Uberlândia, Brasil. E-mail: mfjr@ufu.br. ORCID: https://orcid.org/0000-0001-7174-7177.
} 
vez en cuando, surgen como desafíos presentes en medio de crisis pronunciadas. En estas circunstancias, es aconsejable volver a los clásicos para que no olvidemos que el presente es, ante todo, el resultado del pasado y de un pasado que se ha esforzado por mantener vínculos con la tradición, las costumbres, las formas de dominación, jerarquía social, de organización política. Estas características históricas únicas nos llevan a un insistente retorno al pasado para encontrar los hitos de las crisis actuales y prever alternativas futuras. De ahí la importancia reiterada de volver a los clásicos en el esfuerzo por volver sobre los caminos de aquellos que nos precedieron, para comprendernos mejor. Siguiendo esta tradición, el dossier presenta estudios sobre grandes intérpretes de este campo de investigación, como Florestan Fernandes, Octavio Brandão, José Guilherme Melquior, José de Alencar y Leandro Tocantins, cada uno con su propia especificidad e ideas sobre Brasil, nuestra gente, identidad, integración y otros temas de igual relevancia, análisis cuyo momento de crisis política y social lo hace aún más relevante. Palabras-clave: Brasil. Interpretaciones. Ideas

\title{
Presentation of the special issue \\ Brazilian social and political thinking dossier: searching for the past explanations for this brazilian social and political
}

\begin{abstract}
Studies in the field of Brazilian Social and Political Thought reflect on what we are and, even more, on what we wish to be as a people. These are the questions that, from time to time, surface as challenges present in the midst of pronounced crises. In these circumstances, it is advisable to return to the classics so that we do not forget that the present is first and foremost a result of the past, and of a past that has strived to maintain links with tradition, customs, forms of domination, social hierarchy, of political organization. These unique historical features lead us on an insistent return to the past to find the milestones of present crises and to foresee future alternatives. Hence the repeated importance of returning to the classics in the effort to retrace the ways of those who came before us, to understand ourselves better. Following this tradition, the dossier presents studies on great interpreters of this field of research, such as Florestan Fernandes, Octavio Brandão, Jose Guilherme Melquior, Jose de Alencar and Leandro Tocantins, each with its own specificity and ideas about Brazil, our people, identity, integration and other topics of equal relevance, analyzes whose moment of political and social crisis makes it even more relevant.
\end{abstract}

Keywords: Brazil. Interpretations. Ideas.

Em momentos de crise ganha ainda mais relevância o olhar retrospectivo voltado para os clássicos intérpretes do Brasil, sejam eles canônicos ou não.

O que caracteriza um clássico não é a fama conquistada. Os clássicos o são porque embora tenham produzido seus pensamentos em contextos passados, suas ideias não cessam de sugerir novas questões, contribuindo para a reflexão de nossos dilemas pretéritos e também presentes. Os estudos de explicação do Brasil geralmente apresentam características totalizantes e ensaísticas, refletindo sobre o que somos e, ainda mais, sobre o que queremos e podemos ser. São estas indagações que de tempos em tempos voltam à tona como desafios presentes em meio a crises pronunciadas. Nestas circunstâncias, é aconselhável voltar aos clássicos para que não nos esqueçamos 
Dossiê | Pensamento social e político brasileiro: buscar no passado as explicações para o presente político e social brasileiro (GODOY, José Henrique Artigas de; FREITAS JUNIOR, Moacir)

que o presente é, antes de tudo, resultado do passado, e de um passado que primou por manter elos com a tradição, com os costumes, com as formas de dominação, de hierarquia social, de organização política.

Avessa às revoluções, a formação social e política do Brasil nos legou um país moderno a seu modo, aqui o passado se encontra no presente. Uma gama ampla de intérpretes debruçados sobre o desafio de pensar o Brasil procuraram destacar o aspecto da mudança marcada pela conservação, daí, por exemplo, as teses sobre a modernização conservadora, a revolução passiva, a via prussiana, a revolução pelo alto, a modernização sem modernidade, a mudança dentro da ordem, enfim, a mudança sem mudança.

Esta característica histórica nos conduz a uma insistente volta ao passado para encontrar os marcos das crises presentes e para prospectar as alternativas futuras. Por isso a importância reiterada de retorno aos clássicos no esforço de refazer os caminhos dos que vieram antes de nós, para nos compreendermos melhor. Por isso, não surpreende o esforço contínuo de nossos intelectuais em pensar e repensar o Brasil, seu povo, sua cultura, seus valores, suas instituições.

É nesse aspecto que ganha interesse o dossiê que apresentamos ao público leitor da Revista Argumentos, certos de que poderão encontrar nos artigos aqui reunidos uma ampla e variada oferta de análises sobre textos, contextos e autores clássicos que pensaram o Brasil, suas potencialidades e limites. Em meio à mais pronunciada crise de nossa história, é preciso voltar ao passado para compreender as amarras que nos vinculam às nossas raízes e condicionam nossas alternativas pois, como dizia Florestan Fernandes, temos um passado que encurrala nosso presente.

O dossiê é composto de cinco artigos e uma entrevista, perpassando temas diversos compreendidos pelo campo do Pensamento Social e Político Brasileiro.

O trabalho de Maria Stella D’Agostini apresenta a obra e as ideias de um pensador que, como a própria autora ressalta, é um "marginal" do pensamento brasileiro: Octávio Brandão, pensador marxista da primeira metade do século XX, dirigente do PCB e autor de, entre outros, Agrarismo e Industrialismo, originalmente publicado em 1924, entre outras. O termo "marginal", aqui, tem o sentido de "de fora da margem", de não estar inserido no rol de pensadores reconhecidos como canônicos pela intelligentsia brasileira, o que nos leva a, antes de apresentar as ideias de Octávio 
Dossiê | Pensamento social e político brasileiro: buscar no passado as explicações para o presente político e social brasileiro (GODOY, José Henrique Artigas de; FREITAS JUNIOR, Moacir)

Brandão, relatar o importante debate que a autora faz sobre o próprio pensamento brasileiro enquanto campo científico.

É conhecida a avaliação de Florestan Fernandes (1980) sobre a produção de análises do Brasil e de seus pensadores antes da institucionalização da sociologia como ciência e da adoção de uma metodologia própria para seus estudos. Em seu entender, tais obras tratavam-se de ensaios, trabalhos de menor rigor científico que valeriam para a exposição de ideias, mas não deveriam ser considerados científicos, por não atentarem para os preceitos metodológicos exigidos pelo rigor acadêmico.

No entanto, o fortalecimento do campo do Pensamento Brasileiro como ramo científico especializado nos pensadores que se dedicaram a entender o Brasil, seu povo, sua formação e as ideias e análises que alicerçaram esta jornada, invocou uma nova tecnologia para o trato com os ensaístas. O espaço não nos permite digressão maior, mas autores importantes do campo do Pensamento Brasileiro trabalharam com precisão estas questões, entre os quais Gildo Marçal Brandão (2005), Cristian Lynch (2014), Roberto Schwarz (2014), entre outros.

Nestes termos, portanto, o resgate do "marginal" Octávio Brandão feito se reveste de importância e relevância, na medida em que o pensador produziu suas ideias no curso dos eventos mais importantes do século XX para o Brasil e para o mundo, procurando explicar - e aqui reside suas mais importantes contribuições intelectuais como o Brasil se formou do ponto de vista econômico e social, os efeitos dessa formação especial em nossa sociedade e quais os caminhos que poderíamos trilhar para avançarmos na direção da modernização e do desenvolvimento e no sentido da construção do comunismo brasileiro.

A trajetória de vida de Octávio Brandão, apresentada com maestria pela autora, nos ajuda a entender suas interpretações sobre o Brasil. Alagoano crescido em meio à miséria em que vivia o povo nordestino, formou-se em farmácia e transitava bem pelas ciências minerais, a geografia, a biologia e outras áreas, o que Ihe deu boa noção de metodologia científica, aplicada em seus trabalhos. Militante das causas anarquistas, em um primeiro momento migrou forçado para o Rio de Janeiro, onde teve contato com Astrogildo Pereira, então dirigente do PCB, e com as notícias e obras acerca da Revolução Russa de 1917. 
Dossiê | Pensamento social e político brasileiro: buscar no passado as explicações para o presente político e social brasileiro (GODOY, José Henrique Artigas de; FREITAS JUNIOR, Moacir)

Apropriado do marxismo e de sua teoria e método, Brandão tornou-se pioneiro no uso do materialismo histórico e dialético para entender e interpretar a formação do Brasil até ali. Também é de sua autoria o uso de expressões consagradas pela ciência e pela militância marxista, como marxismo-leninismo e as importantes noções de etapa, tática e estratégia, desprezadas quando de sua exposição, mas totalmente apropriadas pelos partidos de esquerda brasileiros, especialmente pelo $P C B$, décadas depois.

Brandão ainda lançou mão de outros dois importantes instrumentos para a compreensão do Brasil: as noções de rural e urbano, que entendia dialéticas e que são chave para a compreensão de como se deu o ingresso do Brasil na era moderna e na industrialização, e que resultaram nos debates sobre o subdesenvolvimento e a dependência do capitalismo brasileiro, bem como os conceitos de ciclos econômicos na análise da história econômica brasileira.

Por tudo isso, a contribuição de Maria Stella D’Agostini, para além de resgar da "marginalidade" um importante pensador brasileiro, ajuda na construção de nosso campo de pesquisa, ampliando as bases de ideias com as quais podemos interpretar o Brasil de ontem e de hoje.

Também na direção de interpretar a formação da sociedade brasileira, mas pelo viés da formação do nosso capitalismo e das consequências desta especial formação para nossa sociedade, Mariana Davi Ferreira revisita os clássicos ensinamentos de Florestan Fernandes acerca do capitalismo dependente nos países latino-americanos, suas causas e resultados, requerendo a retomada deste debate para ajudar a compreender os problemas atuais pelos quais passa a economia e a sociedade brasileira.

A autora destaca que, considerando uma classificação histórica e temática dos pensadores e ideias sobre o Brasil, as discussões sobre a formação econômica do Brasil, seus efeitos na sociedade e formas de alterarmos o patamar de subdesenvolvimento em que nos encontrávamos ganho maior força a partir dos anos 1930, quando os pensadores brasileiros de então passaram a ocupar-se de pensar o Brasil a partir "de si", ou seja, procurando entender a formação de nosso país e povo para, então, buscar compreender e daí solucionar nossos problemas e deficiências. É o período que Lynch (2014) chama de "paradigma nacionalista periférico", momento em que nossos ideólogos buscaram entender os fatores que nos diferenciavam dos demais países do mundo em termos econômicos, sociais, culturais, enfim, de construção social. 
Dossiê | Pensamento social e político brasileiro: buscar no passado as explicações para o presente político e social brasileiro (GODOY, José Henrique Artigas de; FREITAS JUNIOR, Moacir)

É neste contexto, que coincide com o momento de institucionalização das ciências sociais no Brasil, que Florestan Fernandes desenvolveu seus estudos acerca da formação econômica e social do Brasil, de nossas classes e sobre as consequências desta condição diferenciada. A um só tempo, sua vasta produção intelectual o colocou em debate com os temas mais caros aos pensadores brasileiros da primeira metade do século XX: mudanças sociais, subdesenvolvimento, desenvolvimentismo, papel das classes sociais, cultura e identidade nacionais, papel dos negros na sociedade, enfim, todo um conjunto de análises que buscavam compreender nossa trajetória e explicar os acontecimentos do presente.

Mais especificamente entre os anos 1950-1960, os debates em torno do desenvolvimentismo, a política de desenvolvimento nacional através da industrialização, ganharam maior corpo e profundidade, com diversas teses tentando entender o contexto em que este desenvolvimento poderia se dar, e sob qual direção.

Era o tempo da CEPAL, a primeira contribuição institucionalizada que procurou desvendar os caminhos do capitalismo latino-americano periférico e propor uma solução que pudesse nos promover ao centro da divisão internacional do trabalho, a substituição de importações, modelo de desenvolvimento baseado na industrialização e no aumento da capacidade de produção de cada país. Foram os cepalinos, também, os primeiros a desvendarem os malefícios do sistema de trocas até então vigente, no qual as economias periféricas produziam e vendiam matérias-primas às economias centrais em troca da importação de produtos manufaturados, modelo este que jamais permitiria o desenvolvimento autônomo dos países latino-americanos em função das desigualdades nos termos de intercâmbio. Era também o tempo do ISEB, centro de estudos brasileiros dedicado à análise do capitalismo brasileiro e de soluções para romper com o subdesenvolvimento, por meio de uma estratégia nacionalista de desenvolvimento e inserção autônoma no capitalismo internacional.

Florestan Fernandes vai ingressar neste debate quando o desenvolvimentismo, enquanto modelo, não consegue mais responder a todas as questões que lhes foram colocadas, especialmente ao se observar que, apesar da industrialização e da substituição das importações - que se concluiu - os países subdesenvolvidos não alteraram seu patamar na divisão internacional do trabalho. Ao contrário, seguiram sendo periféricos. 
Dossiê | Pensamento social e político brasileiro: buscar no passado as explicações para o presente político e social brasileiro (GODOY, José Henrique Artigas de; FREITAS JUNIOR, Moacir)

Uma parte das críticas ao desenvolvimentismo serão da lavra da teoria marxista da dependência, cujos formuladores (Rui Mauro Marini, Vânia Bambirra, Theotônio do Santos e outros) defendiam que a posição periférica dos países subdesenvolvidos era fruto direto da superexploração de suas economias pelos países desenvolvidos. A outra parte coube às teorias do capitalismo dependente por associação, cuja maior expressão é a análise de Fernando Henrique Cardoso e Enzo Faletto (1970), além, claro, da crítica de Florestan Fernandes, que ocupa um lugar próprio no processo.

Segundo Florestan Fernandes, a dependência não é uma condição, mas parte da estrutura do capitalismo de então, o que limitava, na prática, o espaço para a autodeterminação econômica dos países. Não se tratava de uma política de desenvolvimento que nos elevaria de patamar, mas da nossa posição na estrutura do sistema.

Partindo desta hipótese, muito bem demonstrada por Mariana Davi Ferreira em seu artigo, o autor conclui que a condição de subdesenvolvimento é parte da estrutura do capitalismo mundial e que as economias periféricas existem para sustentar e alimentar as economias centrais, reproduzindo em seu território os mecanismos de acumulação e transferência de riquezas para as economias desenvolvidas, em um processo que o autor denominou de heterônomo, ou seja, com o centro das economias periféricas instalado nos países centrais, acumulando riquezas para eles ao transferir parte de nossa riqueza para as economias centrais.

Nestes termos, a dependência seria estrutural, parte da dinâmica e da construção do capitalismo mundial. Desde sempre, as economias periféricas nasceram para complementar o processo de enriquecimento das economias centrais, razão pela qual não haveria condições para que os países latino-americanos rompessem com a condição de dependência somente por suas forças, na medida em que toda a lógica do capitalismo industrial de então funcionava naquelas bases de divisão do trabalho.

Por fim, a condição de dependência também se refletiria em nossas classes sociais, cuja estrutura reproduziria tais relações, o que explicaria os motivos pelos quais não tivemos revoluções burguesas semelhantes às dos países centrais e nem nos ocupamos de superar as práticas pré-capitalistas de dominação social, ainda presentes na sociedade brasileira. Nos países centrais, a burguesia lutou e derrotou o feudalismo para se impor. Nos países periféricos, nascemos já sob o signo da colônia, 
Dossiê | Pensamento social e político brasileiro: buscar no passado as explicações para o presente político e social brasileiro (GODOY, José Henrique Artigas de; FREITAS JUNIOR, Moacir)

estruturalmente alocados na condição de dependência econômica, apesar de nossa independência política. Nossas classes não puderam cumprir com seu destino de transformar a realidade porque nossa realidade era outra, diferente da tarefa que foi dada às classes dos países centrais.

Tudo isso está presente no artigo de Mariana Davi Ferreira, que termina com um chamado sobre a atualidade do pensamento de Florestan Fernandes para interpretar os problemas do Brasil e da América Latina. Em um tempo em que o desenvolvimento não é mais a pauta do capitalismo, porque invocar as explicações de Florestan Fernandes para nosso capitalismo dependente, interpretação partida da crítica às teorias do desenvolvimento? Neste aspecto ganha relevância o artigo aqui apresentado, que aponta para a necessidade de revisitar as obras de Florestan Fernandes.

Qual o lugar das tradições e dos valores culturais e regionais face o projeto de modernização do Brasil no século XX? É para responder esta pergunta que Leandro Tocantins, dedicou sua carreira política e intelectual, que encontramos retratada no artigo de Ricardo Lima da Silva, Carlos Henrique Gileno e Ana Paula da Conceição Amorim Pedrosa.

Jornalista, historiador, tecnocrata, poeta e líder político, Tocantins reunia as características recorrentes entre dos intelectuais públicos e engajados brasileiros de seu tempo: formado em jornalismo pela Universidade do Rio de Janeiro, ao mesmo em que formulava teses intelectuais sobre o desenvolvimento regional da região amazônica, as colocava em prática em suas atuações políticas, transformando-as em políticas de intervenção do Governo Federal para a Amazônia, procurando conciliar a modernidade da industrialização que se instalava com as tradições culturais e regionais amazonenses, buscando obter o progresso de modo controlado, criterioso, sem a universalização dos valores, preservando o passado.

Neste sentido, tradição, cultura e passado são os alicerces das ideias de Leandro Tocantins apresentadas no artigo. Influenciado por intelectuais como Gilberto Freyre, Euclides da Cunha, Ortega y Gasset e outros, o pensador buscou criar uma metodologia própria para estudar a região amazônica, a amazonotropicalogia, que unia a sociologia, a antropologia e a ecologia em uma só linha de estudos que fosse capaz de analisar e compreender a complexa relação dos amazonenses com o ambiente - a inserção deles 
Dossiê | Pensamento social e político brasileiro: buscar no passado as explicações para o presente político e social brasileiro (GODOY, José Henrique Artigas de; FREITAS JUNIOR, Moacir)

na floresta e sua intrínseca relação com ela, em termos muito próximos aos da "lusotropicologia" de Gilberto Freyre.

Leandro Tocantins buscava inserir a região amazônica no contexto da modernização brasileira, mas sem abrir mão das tradições regionais e do passado amazônico, marcado pela miscigenação e pela interação com a natureza, fato que, segundo os autores, encarava com uma missão. Para tanto, escolheu o caminho da modernização conservadora, utilizando-a como método para a proposta de desenvolvimento da Amazônia: mudar sem esquecer das tradições, a história e os costumes, que deveriam ser respeitados, uma vez que seriam as bússolas do presente, direcionariam a vida social do presente. Tocantins criticava o individualismo da modernidade e buscava incorporar as novidades às tradições locais. Modernizar, para o autor, não seria abandonar o passado, mas utilizá-lo como guia para o presente e o futuro.

Ao invocar o poder das tradições, o autor entendia que a cultura era a representação da identidade dos povos e que, por assim ser, guardaria em si a totalidade dos costumes, tradições, valores e construções que fundariam aquele povo e aquela sociedade. No especial caso da região amazônica, a condição de sua formação teria resultado em um povo e uma cultura local que deveriam ser preservados, ao mesmo tempo em que a região precisaria integrar-se ao desenvolvimento das demais regiões do país. Foi com esta direção que Tocantins lutou pela integração da Amazônia ao restante do Brasil, propondo o planejamento econômico e estatal para o desenvolvimento da região e aderindo ao movimento liderado por Gilberto Freyre, em defesa das tradições e da cultura regional brasileira, do "modernismo tradicionalista", na contramão do modernismo cosmopolita da Semana de Arte Moderna de São Paulo, de 1922.

Desiludido com a política, Tocantins aderiu ao Golpe de 1964 e viu na Ditadura uma oportunidade de o Estado intervir diretamente na questão amazônica, a fim de integrá-la e de superar o subdesenvolvimento da região. Mas tal integração não se daria de qualquer forma: ela teria de, além de considerar todos os aspectos culturais e tradicionais amazônicos, cuidar para que a integração do território não o degradasse, não eliminasse a relação homem-natureza, ponto fundamental da formação do povo amazonense. 
Dossiê | Pensamento social e político brasileiro: buscar no passado as explicações para o presente político e social brasileiro (GODOY, José Henrique Artigas de; FREITAS JUNIOR, Moacir)

Há ainda muitas mais questões trazidas ao debate pelo trabalho de Ricardo Lima da Silva, Carlos Henrique Gileno e Ana Paula da Conceição Amorim Pedrosa, cuja originalidade e atualidade, em um momento em que o pensamento conservador vem sendo retomado com força em nossa sociedade, é de enorme importância.

Liberalismo, tradição, Estado e mercado também são temas relevantes que o artigo de Anderson Barbosa Paz apresenta sobre a obra de José Guilherme Merquior, intelectual, sociólogo, economista e embaixador brasileiro em diversos países, que se tornou um expoente do pensamento liberal brasileiro.

O artigo de Paz ganha ainda mais importância no momento em que o espectro à direita da política brasileira procura se articular tanto do ponto de um vista prático quanto teórico, procurando formular um campo partido de ideias próprias que, conforme bem delimitou Vera Cepeda (2018), tem defendido a naturalidade das desigualdades sociais e, portanto, insuperáveis pela ação humana, bem como adotado o neoliberalismo como ideologia e condução de suas práticas políticas.

Neste sentido, retomar as ideias de um dos expoentes deste campo se torna relevante para a compreensão da atual situação política brasileira. José Guilherme Merquior morreu jovem, mas teve vida uma vida intelectual muito profícua. Foi membro da Academia Brasileira de Letras e escreveu diversas obras, transitando, no campo ideológico, da social-democracia para o liberalismo social, influenciado por autores clássicos do liberalismo como Raymond Aron, Ralf Dahrendorf, Stuart Mill, Keynes, Hayek, Bobbio, entre outros.

Até pela formação diferenciada, que agregou visões diferentes de mundo dentro do campo liberal (mais à esquerda e mais à direita), Merquior rumou para o liberalismo social com a certeza de que havia um papel a ser cumprido pelo Estado na organização da economia, bem como de que não seria correto confiar totalmente no mercado para a geração e distribuição das riquezas, porque nele a questão da igualdade não se solucionaria. Sem igualdade, não se poderia falar em liberdade econômica.

A seu ver, os pilares de uma sociedade livre seriam a economia, a eficiência e a democracia. O Estado não deveria dirigir a economia, mas poderia estimulá-la, antecipando processos a fim de acelerar os resultados. Ele entendia o liberalismo como uma "cosmovisão", uma forma de pensamento e ação para o progresso que não poderia ser reduzido à questão do liberalismo de mercado. 
Dossiê | Pensamento social e político brasileiro: buscar no passado as explicações para o presente político e social brasileiro (GODOY, José Henrique Artigas de; FREITAS JUNIOR, Moacir)

Sua busca era por encontrar um equilíbrio entre as liberdades e o peso da máquina social; a economia e a política, entendendo que não haveria liberdade sem igualdade. De Aron, colheu a busca pela equidade entre liberdade e mercado, buscando no Estado o agente regulador destas tensões, ainda que de modo relativo. De Dahrendorf, absorveu a ideia de que o conflito social não se dá entre classes, mas entre os direitos adquiridos ao longo dos tempos e a real capacidade da sociedade de efetiválos.

O Estado deveria agir, então, para corrigir as imperfeições do mercado, de modo a sanar as diferenças entre as pessoas, permitindo que todos tivessem as mesmas oportunidades no "ponto de partida", ou seja, que as desigualdades, que são parte da estrutura da sociedade, pudessem ser dirimidas ou remediadas, permitindo, a partir daí, que cada indivíduo trilhasse seu caminho e aproveitasse as oportunidades surgidas. A igualdade de condições seria uma ferramenta para ampliar a liberdade individual.

Sua busca de um ponto de equilíbrio entre o estatismo de esquerda e a "estadofobia" dos neoliberais é o que o distanciou de Hayek, um de seus influenciadores mais profundos, mas com quem também manteve divergências importantes. Merquior partia da realidade brasileira para formular os conceitos, enquanto que os demais pensadores liberais importavam tais conceitos.

Entre outras questões suscitadas pelo artigo de Anderson Paz, encontram-se as aproximações e distanciamentos entre os pensamentos de Hayek e Merquior. Neste sentido, enquanto Hayek não confiava nenhum papel relevante ao Estado na economia que não fosse a definição mais geral das "regras do jogo", Merquior o entendia como um agente regulador capaz de administrar as tensões advindas da desigualdade social. Hayek entendia que a única liberdade que interessava era a econômica, uma vez que, sem essa, as demais não existiriam de fato. Merquior, por seu turno, considerava a igualdade como o valor mais importante e entendia que, sem ela, não se poderia falar em liberalismo.

Por fim, retomando uma tradição do pensamento brasileiro de recorrer à literatura para interpretar o Brasil, David Simões apresenta a obra de José de Alencar de uma perspectiva diferente da habitual: a de um pensador do Brasil e das contradições de sua época expressas por meio da literatura. 
Dossiê | Pensamento social e político brasileiro: buscar no passado as explicações para o presente político e social brasileiro (GODOY, José Henrique Artigas de; FREITAS JUNIOR, Moacir)

A expansão do campo de pesquisa sobre o Pensamento Brasileiro, permitiu que autores que até então não entraram propriamente no rol canônico de pensadores do Brasil fossem revisitados e tivessem suas obras reanalisadas, alargando o leque de elementos analíticos da formação de nossa sociedade e de nosso Estado. José de Alencar é um destes casos. Romancista, teatrólogo, deputado, Ministro da Justiça, conselheiro real e militante do Partido Conservador no século XIX, o romancista brasileiro, que tornou-se clássico por obras como O Guarani, Iracema e outras, tinha na literatura, no teatro e na política os meios de expressar suas ideias sobre o Brasil. Em suas obras, temas importantes para sua época foram debatidos, como a ascensão da família burguesa, a escravidão, a participação das mulheres na política e na sociedade, bem como a construção da identidade nacional e da nacionalidade brasileira.

Olhando as obras de Alencar em conjunto, David Simões aponta que delas emerge uma visão geral sobre o Brasil, sustentada pela literatura (por meio da qual debatia temas da nacionalidade e identidade nacional), pelo teatro (cujas obras buscavam passar uma mensagem de moralização da sociedade da Corte) e dos discursos políticos na Câmara, nos quais defendia as instituições e valores da Monarquia.

A miscigenação das raças branca e indígena era, a seu ver, a base da identidade nacional brasileira, o diferencial de nosso povo, o que nos constituía enquanto tal. Notemos: os negros não estavam presentes no argumento, provavelmente porque Alencar não queria tocar no tema da escravidão, que na maior parte do período histórico em que atuou não era ainda o debate principal na sociedade, além, claro, das ideias racialistas europeias já presentes na sociedade de então.

O tema da miscigenação foi retomado pelos autores da "geração de 1870" (ALONSO, 2000). De um lado, Nina Rodrigues, Sílvio Romero, Tobias Barreto e outros tantos, influenciados pelo pensamento eugenista, amparado em doutrinas como o darwinismo social e o evolucionismo cultural, focavam suas interpretações na ideia de degeneração moral dos negros, enquanto, por outro lado, também se fortaleciam as tendências culturalistas críticas das análises racialistas, explicando os comportamentos sociais como resultantes de pressupostos histórico-culturais, daí derivando a tese de que a degeneração não seria própria do escravo mas, antes, das condições sociais próprias do regime de escravidão, que degenerava brancos e negros, senhores e 
Dossiê | Pensamento social e político brasileiro: buscar no passado as explicações para o presente político e social brasileiro (GODOY, José Henrique Artigas de; FREITAS JUNIOR, Moacir)

escravos, seguindo as interpretações de José Bonifácio e dos movimentos europeus contra a escravidão.

Alencar se envolveu intensamente no debate da época. Para o romancista, a convivência do escravo com seu senhor tenderia a civilizar o escravo, de forma que lentamente haveria um processo social de regeneração moral. Joaquim Nabuco protagonizou nas páginas da imprensa da época um agressivo debate crítico às ideias de Alencar. Em um conjunto variado de artigos Nabuco atacava Alencar e este respondia no mesmo tom em edições posteriores. O debate público deixava clara a oposição que se gestava entre os pensadores favoráveis e resistentes à abolição, os culturalistas e os eugenistas. Os argumentos de Alencar só começaram a ser superados no início do século XX, com Manoel Bonfim, Alberto Torres e, mais tarde, com Gilberto Freyre, que representou a superação paradigmática que retirou a carga preconceituosa atribuída à miscigenação, como no argumento de Alencar.

Conservador, Alencar criticava o panorama de mudanças, especialmente no tangente à questão racial, e por associação à escravidão, e à da emancipação das mulheres. Alencar defendia mudanças sociais lentas, graduais, sem mudanças abruptas, seguindo a 'ordem natural das coisas'. Assim, para as mulheres, entendia ser o melhor caminho seu ingresso na sociedade e na política de modo tutelado pelos homens, dando tempo para que elas pudessem se integrar por completo ao ambiente da cidadania. No caso da escravidão, entendia que a libertação dos escravos e sua inclusão na sociedade não se daria por decreto, mas apenas após uma mudança profunda e lenta dos costumes e valores sociais, em um processo natural de transformação em que a presença dos negros e sua incorporação fossem lentamente sendo aceitas, até se completar no longo prazo.

Os dilemas que Alencar enfrentou e o modo como lidou com eles, bem como o debate de temas polêmicos, que ainda hoje suscitam muitas contradições, conferem ao pensamento do autor uma expressiva relevância para a compreensão do contexto intelectual e político do II Reinado, assim como suscita questões que ainda hoje são relevantes no debate público. O estudo sobre Alencar oferecer elementos novos para interpretar a formação da sociedade brasileira, encerrando com chave de ouro a coletânea de textos que trazemos ao público neste dossiê. 
Dossiê | Pensamento social e político brasileiro: buscar no passado as explicações para o presente político e social brasileiro (GODOY, José Henrique Artigas de; FREITAS JUNIOR, Moacir)

Como se pode ver ao final dessa pequena introdução ao dossiê, a riqueza do campo do Pensamento Social e Político Brasileiro está nas possibilidades amplas e variadas que nosso objeto de estudos - o Brasil - possibilita aos que se aventuram a desnudar suas mazelas, a compreender suas vicissitudes, suas contradições; as razões e porquês da adoção de determinados caminhos e não de outros; as possibilidades que temos ainda para explorar.

Mas, e principalmente, nossa busca enquanto campo científico é dotar os intérpretes do Brasil dos apetrechos necessários para esta empreitada, retomando aquilo que há de universal em nosso passado para nos ajudar na tarefa de entender nosso presente e, se possível, planejar nosso futuro.

Nos tempos atuais, nada mais urgente e necessário.

\section{Bibliografia}

ALONSO, Angela. Crítica e contestação: o movimento reformista da geração de 1870. Revista Brasileira de Ciências Sociais, v. 15, n. 44, p. 35-55, 2000

BRANDÃO, Gildo M. Linhagens do Pensamento Político Brasileiro. DADOS Revista de Ciências Sociais, v. 48, no 2, p. 231-269, 2005.

CARDOSO, Fernando Henrique e FALETTO, Enzo. Dependência e Desenvolvimento na América Latina: Ensaio de Interpretação Sociológica. Rio de Janeiro: Zahar, 1970.

CEPÊDA, Vera Alves. A Nova Direita no Brasil: contexto e matrizes conceituais. Mediações, LONDRINA, V. 23 N. 2, P. 75-122, mai./ago. 2018

LYNCH, C. Por que Pensamento e Não Teoria? A imaginação Político-Social Brasileira e o Fantasma da Condição Periférica. DADOS - Revista de Ciências Sociais, vol. 56, no 4, 2014. p. 727-767.

LYNCH, Christian Edward Cyril. Cartografia do pensamento político brasileiro: conceito, história, abordagens. Rev. Bras. Ciênc. Polít., Brasília, n. 19, p. 75-119, Apr. 2016. http://dx.doi.org/10.1590/0103-335220161904

SCHWARZ, R. As Idéias fora do Lugar. São Paulo: Penguin, 2014. 